\title{
Thyrotoxicosis Presenting First Time as Hypokalemic Paralysis: A Rare Case Report
}

\author{
Soni Kumar ${ }^{1}$, Trilok C Guleria ${ }^{2}$, Pratibha Himral ${ }^{3}$, Santosh Kumar ${ }^{4}$, Roshan Lal ${ }^{5}$
}

\begin{abstract} thyrotoxicosis presented for the first time as hypokalemic paralysis.

Keywords: Hypokalemia, Hypokalemic periodic paralysis, Quadriplegia, Thyrotoxicosis.

AMEl's Current Trends in Diagnosis \& Treatment (2020): 10.5005/jp-journals-10055-0086
\end{abstract}

Thyrotoxicosis has various clinical manifestations, ranging from its usual features to some rare presentations. Thyrotoxicosis presenting as acute quadriplegia is a very rare phenomenon and is attributed to hypokalemia. Thyrotoxic hypokalemic periodic paralysis is a known but rare manifestation, and a first presentation is relatively unknown in the past. Here, we present a case of middle-aged Asian male in whom

\section{INTRODUCTION}

Thyrotoxicosis presenting for first time as hypokalemic periodic paralysis (HPP) is a rare entity. It is much more common in patients of Asian descent when compared to the Western population. It may present as rapidly evolving quadriplegia and life-threatening emergency and lead to a diagnostic dilemma for the physicians, and unfamiliarity with the entity can be fatal. Although thyrotoxicosis is more common in women, thyrotoxic periodic paralysis (TPP) is more common in men when compared to women. Here, we report the case of thyrotoxicosis presenting first time as HPP in a middleaged male farmer who previously had no history of thyroid disease.

\section{Case Description}

A 43-year-old male patient, farmer by occupation, presented to the emergency department with complains of weakness of all four limbs for 2 days without fever. Next day at 6 AM, the patient tried to get up from sleep to pass urine and realized that he is not able to move his legs. He also could not move side to side in the bed. At this time, the patient could move his arms. This weakness progressed within hours so that the patient could not move his arms as well.

On examination, there was a visible neck swelling involving both lobes of thyroid, moving with deglutition, soft to firm, bilaterally symmetrical, nontender, went unnoticed by the patent as it was there for 8-10 months. On neurological examination, the patient was conscious, oriented with normal higher mental functions and no cranial nerve involvement. Patient had hypotonia with power of $1 / 5$ in all muscles groups at all joints. Deep tendon reflexes were diminished, and superficial reflexes were present. Planters were bilaterally flexors. There were no signs of raised intracranial tension. Cardiovascular examination was normal except for pan-systolic murmur present on the precordium. There were no other signs.

On routine investigations, all were normal except for serum potassium of $1.8 \mathrm{mEq} / \mathrm{L}$. Further investigations were aimed at finding the cause of hypokalemia. The thyroid function test (TFT) showed a depressed thyroid-stimulating hormone- $0.03 \mathrm{mU} /$ $\mathrm{mL}$ (normal 0.5-4.7), raised free $\mathrm{T}_{4}-2.8 \mathrm{ng} / \mathrm{dL}$ (normal 0.6-2.0), and $\mathrm{T}_{3}-200 \mathrm{ng} / \mathrm{dL}$ (normal 70-190), although clinically there were no features of thyrotoxicosis. His TPO antibody was $74 \mathrm{IU} / \mathrm{mL}$
${ }^{1,3-5}$ Department of Medicine, Shri Lal Bahadur Shastri Government Medical College, Mandi, Himachal Pradesh, India

${ }^{2}$ Department of Otolaryngology-Head and Neck Surgery, Dr Radhakrishnan Government Medical College, Hamirpur, Himachal Pradesh, India

Corresponding Author: Trilok C Guleria, Department of Otolaryngology-Head and Neck Surgery, Dr Radhakrishnan Government Medical College, Hamirpur, Himachal Pradesh, India, Phone: +91 9418706446, e-mail: tcguleria@gmail.com

How to cite this article: Kumar S, Guleria TC, Himral P, et al. Thyrotoxicosis Presenting First Time as Hypokalemic Paralysis: A Rare Case Report. AMEl's Curr Trends Diagn Treat 2020;4(1):31-32.

Source of support: Nil

Conflict of interest: None

(normal <35). Other causes of hypokalemia, that is gastrointestinal cause, familial hypokalemic paralysis and chronic diuretic use, were excluded after the detailed history and thorough investigations. The above mentioned test results along with clinical signs of a hyperdynamic state confirmed the diagnosis of thyrotoxicosis; with no past history, this was the first presentation of the illness. The patient was immediately started on intravenous potassium replacement. The patient gradually improved over the next 12 hours and regained full power in 24 hours.

A final diagnosis of thyrotoxic HPP (THPP) was made, and the patient discharged on tablets carbimazole, propranolol, and potassium supplements. He was followed up regularly, and at the end of 2 months TFT was normal. His propranolol was gradually tapered off, and he had no fresh attacks even after 2 months of complete propranolol withdrawal.

\section{Discussion}

Hyperthyroidism is a common entity, but its presentation as HPP is most unusual. The first case of nonspecific periodic paralysis was described in 1882. Hypokalemic periodic paralysis association with hyperthyroidism was described by Jakman and Jones. ${ }^{1,2}$ It is a rare complication of hyperthyroidism, more common in Asian men between second and fourth decades of life. Proximal muscles of 
limb (lower > upper) are affected with sparing of higher mental functions, sensory system, and cranial nerves. Patients can present with cardiac arrhythmia, respiratory failure, and thyrotoxicosis crisis. $^{3-5}$ The exact incidence of THPP is not known in Indian population. In a retrospective study done by Kalitha et al., 52 patients presented as hypokalemic paralysis in 11 years of which only 9 were diagnosed as THPP. ${ }^{6}$

A differential diagnosis of barium poisoning, familial periodic paralysis, and TPP should be considered. Familial periodic paralysis is differentiated by positive family history, earlier onset, and lack of hyperthyroidism. Further, it is transmitted as autosomal-dominant disorder and more common in white population, ${ }^{7}$ while THPP is found more in males of Asian/Oriental descent.

The primary defect in TPP is an intracellular sequestration of potassium with normal potassium in the body. Thyroid hormone changes the plasma membrane permeability to potassium by increasing the $\mathrm{Na} / \mathrm{K}$-ATPase activity. ${ }^{8,9}$ In contrast, in familial periodic paralysis, the intracellular shift of potassium is $\mathrm{Na} / \mathrm{K}$ ATPase independent, and an increase in nonaldosterone mineralocorticoids is present. It responds well to treatment with spironolactone. ${ }^{10}$

Treatment of hyperthyroidism is mainly done with anti-thyroid drugs and are central to the management of TPP. Urgent correction of potassium levels is the initial treatment. Patients with potassium concentrations above $2.5 \mathrm{mmol} / \mathrm{L}$ and mild weakness should be treated with $80 \mathrm{mmol} / 24$ hour of oral potassium. Patients presenting with potassium concentrations below $2.5 \mathrm{mmol} / \mathrm{L}$ or with symptoms of paralysis should be treated with intravenous potassium at a rate of $20 \mathrm{mmol} /$ hour. ${ }^{11}$ In the present case, the patient was put on antithyroid drugs to which he responded nicely. Propranolol was added initially to counter the peripheral effects of thyrotoxicosis and improve the muscle strength. Long-term treatment of TPP entails control of hyperthyroidism. ${ }^{12}$

\section{Conclusion}

Hyperthyroidism is an uncommon but treatable cause of HPP. This case highlights the importance of entertaining this important possibility in these patients for an early and effective management.

\section{References}

1. Standury JB. The metabolic basis of inherited disease. 2 nd edn, New York: McGraw-Hill; 1966. p. 905.

2. Jackman RL, Jones RE. Hyperthyroidism and periodic paralysis. Arch Intern Med 1964;113:657-664. DOI: 10.1001/archi nte.1964.00280110037007.

3. Darrow M, Werner K, Rowley A. Thyrotoxic periodic paralysis: two case studies. Arch Phys Med Rehabil 1995;6(7):685-687. DOI: 10.1016/ S0003-9993(95)80641-5.

4. Robert H, Gaeta TJ, Melniker L. Thyrotoxic periodic paralysis and intravenous propranolol in emergency setting. J Emerg Med 2000;18(2):199-202. DOI: 10.1016/S0736-4679(99)00194-8.

5. Davidson ET, Davidson MJ. Triiodine toxicosis with hypokalemic periodic paralysis and ventricular tachycardia. J Electrocardiol 1995;28(2):161-164. DOI: 10.1016/S0022-0736(05)80288-2.

6. Kalitha J, Goyal G, Bhoi SK, et al. Comparative study of thyrotoxic periodic paralysis from idiopathic hypokalaemic periodic paralysis: an experience from India. Ann Indian Acad Neurol 2012;15(3):186-190. DOI: 10.4103/0972-2327.99708.

7. Van Dam GM, Reisman Y, Van Weiringen K. Hypokalemic periodic paralysis: case report and review of an oriental syndrome. Neth J Med 1996;49(2):90-97. DOI: 10.1016/0300-2977(96)00014-9.

8. Deitch S, Davis D. Hypokalemic thyrotoxic periodic paralysis. Am J Emerg Med 2001;19(1):85-86. DOI: 10.1053/ajem.2001.10027.

9. Kjeldsen K, Norgaard A, Gotzsche CO, et al. Effect of thyroid function on number of $\mathrm{Na}-\mathrm{K}$ pumps in human skeletal muscle. Lancet 1984;2(8393):8-10. DOI: 10.1016/S0140-6736(84)91996-2.

10. Venkat RR, Jeffcote B, Roy B. Thyrotoxic periodic paralysis: A case report and review of litrature. J Emerg Med 1999;17(1):43-45. DOI: 10.1016/S0736-4679(98)00122-X.

11. Hope RA, Longmore JM, MCManus SK, et al. Potassium. Oxford Handbook of Clinical Medicine. 4th edn., Oxford: Oxford University Press; 1999. p.640.

12. Paul B, Hirudayaraj P, Baig MW. Thyrotoxic periodic paralysis: An unusual presentation of weakness. Emerg Med J 2003;20(5):e7. DOI: 10.1136/emj.20.5.e7. 